\section{Category}

Synthesis of

Heterocycles

\section{Key words}

diazo compounds

[3+2] cycloaddition

pyrazoles

alkynes

difluoromethylation

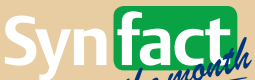
of the

P. K. MYKHAILIUK* (ENAMINE LTD., KYIV AND TARAS SHEVCHENKO NATIONAL UNIVERSITY OF KYIV, UKRAINE)

In Situ Generation of Difluoromethyl Diazomethane for [3+2] Cycloadditions with Alkynes

Angew. Chem. Int. Ed. 2015, DOI: 10.1002/anie.201501529.

\title{
In Situ Generation of Difluoromethyl Diazomethane. Synthesis of Pyrazoles
}<smiles>NCC(F)F</smiles>

(2 equiv)

$\mathrm{R}^{1}=\mathrm{CO}_{2} \mathrm{R}, \mathrm{C}(\mathrm{O}) \mathrm{R}, \mathrm{C}(\mathrm{O}) \mathrm{NHMe}, \mathrm{Ar}, \mathrm{P}(\mathrm{O}) \mathrm{Ph}_{2}$ $\mathrm{R}^{2}=\mathrm{H}, \mathrm{CO}_{2} \mathrm{Me}, \mathrm{CO}_{2} \mathrm{Et}, \mathrm{CF}_{3}$

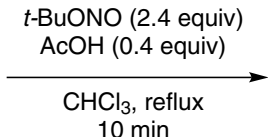

$10 \mathrm{~min}$
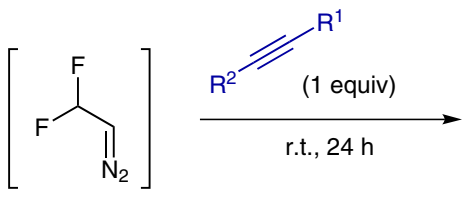

r.t., $24 \mathrm{~h} \longrightarrow$

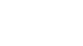

Significance: Incorporation of fluorine in pharmaceutical or agrochemical targets is often advantageous for modulation of physicochemical and biological properties. Thus, development of new strategies to incorporate fluorinated motifs is valuable to several industries. Mykhailiuk reports the generation of difluoromethyl diazomethane, followed by its subsequent cycloaddition with alkynes. In situ generation of trifluoromethyl diazomethane was initially described in a protocol which has enabled safe application of this intermediate in synthesis of diverse motifs (B. Morandi, E. M. Carreira Angew. Chem. Int. Ed. 2010, 49, 938). The method, however, was not applicable to the formation of difluoromethyl diazomethane. In the current work, the author describes a solution to this problem, wherein utilization of $t$-BuONO in non-aqueous media furnishes the desired intermediate. A related publication from the same laboratory describes the use of substituted difluoromethyl diazomethanes $\left(\mathrm{RF}_{2} \mathrm{C}-\mathrm{CN}_{2} ; \mathrm{R} \neq \mathrm{H}\right)$ in a domino reaction with alkynes forming similar pyrazole products. The method utilizes $\mathrm{NaNO}_{2}$ as an oxidant in an aqueous reaction, but cannot be used to efficiently access difluoromethyl substituted pyrazoles (P. K. Mykhailiuk Org. Biomol. Chem. 2015, 13, 3438).
Comment: The generated difluoromethyl diazomethane was utilized in a one-pot [3+2] cycloaddition with alkynes to furnish substituted pyrazoles. As is typical with cycloadditions, alkynes bearing more electron-withdrawing substituents led to product formation in higher yields. The regioselectivity of the cycloaddition was generally high with only the electronically favored products being observed in most cases. Notably, the protocol was amenable to scale synthesis ( 1.5 gram). The structure of the final products was unambiguously confirmed by single-crystal X-ray crystallography. Further studies on the synthetic applications of this protocol may establish this intermediate as a useful addition to the currently available approaches of incorporating difluoromethyl substituents.

Review: On pyrazoles in the agrochemical industry: F. Giornal, S. Pazenok, L. Rodefeld, N. Liu, J.-P. Vors, F. R. Leroux J. Fluorine Chem. 2013, 152, 2-11.
SYNFACTS Contributors: Victor Snieckus, Jane Panteleev (Pfizer) Synfacts 2015, 11(6), 0596 Published online: 18.05.2015 Dol: 10.1055/s-0034-1380833; Reg-No.: V05615SF 